\title{
PENGEMBANGAN PERPUSTAKAAN SEKOLAH BERBASIS TEKNOLOGI INFORMASI DI SMA NEGERI 2 DAN SMA NEGERI 3 PADANG
}

\author{
Elva Rahmah*1, Emidar ${ }^{2}$, Zulfikarni ${ }^{3}$ \\ ${ }^{1,2}$ Universitas Negeri Padang \\ ${ }^{3}$ Jurusan Bahasa dan Sastra Indonesia dan Daerah, Fakultas Bahasa dan Seni \\ J1. Prof. Dr. Hamka Kampus UNP 25131, telp/fax 0751-7053363 \\ e-mail: elva@fbs.unp.ac.id
}

\begin{abstract}
The purpose of science and technology activities for the Society (IbM) is to solve problems in the school library by providing understanding and management of libraries to library officer or teachers placed in the library to be able to manage the school library based on information technology in accordance with established standards. In this activity, it will solve the problem completely from conceptual understanding and conducting school library management practices based on information technology with the implementation of library automation system using Senayan Library Management System (SLiMS) and socialization of information literacy in the school library.The method offered to solve the problem of school library management based on information technology is the training is used lecturing method, question and answer, group discussion, and practice. Then this is followed by information socialization activities information technology-based information for all school members. Training activities accomplished properly according to the expected objectives of the program. This activity received a positive response from various parties and trainees can apply the use of SLiMS software in school library management. From the socialization activities for information literacy performed by involving all elements schools can increase their citizens' understanding of various sources of information that can be utilized. So hopefully the school library can provide better service and the existence of school libraries will contribute significantly to the society.
\end{abstract}

Keywords - school library, Senayan Library Management System (SLiMS), information literacy

\begin{abstract}
Abstrak
Tujuan kegiatan Iptek bagi Masyarakat (IbM) adalah untuk memecahkan masalah di perpustakaan sekolah dengan memberikan pemahaman dan pengelolaan perpustakaan kepada petugas perpustakaan atau guru yang ditempatkan di perpustakaan untuk dapat mengelola perpustakaan sekolah berdasarkan teknologi informasi di sesuai dengan standar yang ditetapkan. Dalam kegiatan ini, akan menyelesaikan masalah sepenuhnya dari pemahaman konseptual dan pelaksanaan praktik pengelolaan perpustakaan berbasis teknologi informasi dengan penerapan sistem otomasi perpustakaan dengan menggunakan Senayan Library Management System (SLiMS) dan sosialisasi literasi informasi di perpustakaan sekolah. Metode ditawarkan untuk memecahkan masalah pengelolaan perpustakaan sekolah berbasis teknologi informasi yaitu pelatihan digunakan metode ceramah, tanya jawab, diskusi kelompok, dan praktik. Kemudian dilanjutkan dengan kegiatan sosialisasi informasi berbasis teknologi informasi untuk semua anggota sekolah. Kegiatan pelatihan dilaksanakan dengan benar sesuai dengan tujuan program yang diharapkan. Kegiatan ini mendapat respon positif dari berbagai pihak dan peserta pelatihan dapat menerapkan penggunaan perangkat lunak SLiMS di lingkungan pengelolaan perpustakaan sekolah. Dari kegiatan sosialisasi untuk melek informasi yang dilakukan dengan melibatkan seluruh elemen sekolah dapat meningkatkan pemahaman warganya terhadap berbagai sumber informasi yang dapat dimanfaatkan. Sehingga diharapkan perpustakaan sekolah dapat memberikan layanan yang lebih baik dan keberadaan perpustakaan sekolah akan memberikan kontribusi yang signifikan bagi masyarakat.
\end{abstract}

Kata kunci-perpustakaan sekolah, Senayan Library Management System (SLiMS), literasi informasi 


\section{PENDAHULUAN}

Seiring dengan perkembangan teknologi informasi yang pesat, kebutuhan pengguna informasi juga semakin meningkat baik kuantitas maupun kualitasnya yaitu akses informasi yang lebih cepat dan lebih luas. Teknologi informasi saat ini telah masuk ke seluruh aspek kehidupan dan mendorong seluruh instansi atau lembaga termasuk perpustakaan sekolah, untuk mau menerima dan menggunakannya. Teknologi informasi menjanjikan peningkatan mutu pelayanan perpustakaan seperti masalah kecepatan dan efisiensi kerja yang memang dibutuhkan oleh institusi yang bekerja di bidang pelayanan informasi seperti perpustakaan.

Perkembangan teknologi informasi telah mengubah paradigma perpustakaan sekolah yang bersifat tradisional ke perpustakaan modern yang berbasis teknologi informasi. Kemampuan pengguna dalam menggunakan teknologi dan kesadaran terhadap teknologi merupakan aspek penting yang mendorong perubahan perpustakaan sekolah yang modern. Pustakawan yang bekerja di bidang pengelolaan dan pelayanan informasi dituntut selalu meningkatkan kompetensinya, terutama kompetensi bidang teknologi informasi agar dapat melayani pengguna informasi secara profesional. Di sisi lain, semakin kompleksnya koleksi perpustakaan, data peminjaman, transaksi dan sirkulasi koleksi perpustakaan, saai ini muncul kebutuhan akan penggunaan teknologi informasi untuk otomatisasi proses yang ada diperpustakaan. Sistem yang dikembangkan dengan pemikiran dasar bagaimana kita melakukan otomatisasi terhadap berbagai proses kegiatan di perpustakaan, kemudian dikenal dengan sebutan sistem otamasi perpustakaan (library automation system). Otomasi perpustakaan adalah sebuah proses pengelolaan perpustakaan dengan menggunakan bantuan teknologi informasi.

Dalam undang-undang perpustakaan nomor 43 tahun 2007, Bab V, Pasal 14 ayat 2: setiap perpustakaan menerapkan tata cara layanan perpustakaan sesuai dengan kemajuan teknologi informasi dan komunikasi (TIK). Dan pada Bab V, Pasal 14, ayat (6) dan (7): layanan perpustakaan terpadu diwujudkan melalui kerjasama antar perpustakaan dan layanan perpustakaan secara terpadu dilaksanakan melalui jejaring telematika.

Menurut Pendit (2007), perkembangan teknologi baru di bidang komputer dan informasi membawa dua hal sekaligus yaitu harapan dan kekuatiran. Terkandang keduanya sama besar mempengaruhi hidup kita; terkadang yang satu lebih kuat dari pada yang lainnya. Teknologi baru juga hampir selalu memerlukan solusi baru karena biasanya selalu harus ada perubahan dan setiap perubahan itu menimbulkan perombakan, baik besar maupun kecil.

Konsekuensi dari terjadinya perubahan dalam paradigma perpustakaan sekolah, mengharuskan perlunya keberanian dari para pengelola perpustakaan sekolah untuk melakukan inovasi dan pembaruan-pembaruan dalam mengelola perpustakaannya, pada berbagai kegiatan dan operasinya yang tentunya berhubungan dengan perkembangan teknologi informasi.

Hadirnya teknologi informasi harus bisa dipahami dan dimanfaatkan secara positif, kreatif dan konstruktif oleh pengelola perpustakaan sekolah. Berhadapan dengan fenomena perubahan yang terjadi, pustakawan harus memiliki kemampuan melihat dengan jelas apa yang sesungguhnya berubah dan apa yang tetap sama (Siregar, 2004:37).

Pemanfaatan teknologi informasi di perpustakaan sekolah sudah seharusnya dilakukan, agar perpustakaan tetap diminati dan dapat memberikan kepuasan kepada pemustakanya. Di sisi lain penggunaan teknologi informasi telah banyak membantu pengelola perpustakaan (pustakawan) untuk meningkatkan mutu pelayanan dan memperkenalkan berbagai jenis layanan baru yang sebelumnya tidak mampu dilakukan perpustakaan sekolah.

Berdasarkan pengamatan ternyata banyak sekolah terutama SD/MI belum memanfaatkan teknologi informasi khususnya komputer untuk pengelolaan perpustakaan. Kalau di lihat di lapangan rata-rata sekolah sudah memiliki komputer. Bahkan ada yang khusus di letakan di perpustakaan sekolah tetapi sebagian besar sekolah belum memanfaatkan komputer untuk pengelolaan kegiatan perpustakaan. Belum di manfaatkannya komputer untuk kegiatan pengelolaan perpustakaan di sekolah di sebabkan berbagai faktor mulai dari tidak mampunya pengelola perpustakaan sekolah untuk menggunakannya untuk kegiatan pengelolaan perpustakaan sekolah.

Suherman (2009:32) mengatakan pustakawan sekolah adalah tenaga kependidikan berkualifikasi serta profesional yang bertanggung jawab atas perencanaan dan pengelolaan 
perpustakaan sekolah, didukung oleh tenaga yang mencukupi, bekerja sama dengan semua anggota komunitas sekolah dan berhubungan dengan perpustakaan umum dan lain-lainnya.

Dewasa ini perpustakaan sekolah sedang digalakan pemerintah. Sehubungan dengan itu, pemerintah pun menganjurkan agar setiap sekolah memiliki perpustakaan sesuai dengan kemampuan masing-masing. Tidak terkecuali di Sekolah Menengah Atas Negeri (SMA N) di Kota Padang. Tetapi pada pelaksanaannya perpustakaan SMA N di Kota Padang yang ada sebagian besar belum memanfaatkan komputer untuk kegiatan pengelolaan dan pelayanan perpustakaan. Melihat kondisi tersebut, maka Tim pengabdian kepada masyarakat memandang perlu diselenggarakan sebuah program memberikan bantuan dalam bentuk pelatihan pengelolaan perpustakaan sekolah berbasis teknologi informasi.

Pentingnya penyelenggaraan perpustakaan sekolah mengacu kepada Undang-undang Nomor 20 Tahun 2003 tentang Sistem Pendidikan Nasional, terutama pada pasal 45. Pasal tersebut menyatakan bahwa setiap satuan pendidikan formal dan nonformal menyediakan sarana dan prasaran yang memenuhi keperluan pendidikan sesuai dengan pertumbuhan dan perkembangan potensi fisik, kecerdasan, intelektual, sosial, emosional, dan kejiwaan peserta didik.

Hal tersebut juga ditegaskan dalam Peraturan Pemerintah Nomor 19 tahun 2005 tentang Standar Nasional Pendidikan pada Pasal 42 dan Pasal 43 tentang Standar Sarana Prasarana. Pada intinya, pasal tersebut menyatakan bahwa setiap sekolah wajib memiliki sarana, salah satu yang utama adalah buku dan sumber belajar.

Dalam undang-undang Nomor 43 Tahun 2007 tentang Perpustakaan, pada Pasal 23 ayat 1 disebutkan setiap sekolah/madrasah menyelenggarakan perpustakaan yang memenuhi Standar nasional perpustakaan dengan memerhatikan Standar Nasional Pendidikan. Pada ayat berikutnya disebutkan perpustakaan sekolah/madrasah wajib memiliki koleksi buku teks pelajaran yang ditetapkan sebagai buku teks wajib pada satuan pendidikan yang bersangkutan dalam jumlah yang mencukupi untuk melayani semua peserta didik dan pendidikan. Selain koleksi buku teks pelajaran, perpustakaan sekolah dan madrasah diharuskan mengembangkan koleksi lain yang mendukung pelaksanaan kurikulum.

Untuk mengatur lebih lanjut tentang penyelenggaraan perpustakaan sekolah, pemerintah juga telah mengeluarkan beberapa peraturan, di antaranya Peraturan Menteri Pendidikan Nasional (Permendiknas) Nomor 24 Tahun 2007 tentang Standar Sarana dan Prasarana untuk Sekolah Dasar/Madrasah Ibtidaiyah (SD/MI). Dalam Permendiknas ini diatur tentang sarana dan prasarana yang harus disediakan oleh sekolah, termasuk didalamnya penyediaan buku dan perabotan serta perlengkapan perpustakaan.

Adapun kebijakan pemerintah mengenai jenis buku yang harus di sediakan terdapat dalam Permendiknas Nomor 2 Tahun 2008 tentang Buku. Kemudian mengenai sumber pendanaan perpustakaan sekolah, telah diatur pada Permendiknas Nomor 2 Tahun 2008 tersebut, di mana pada Pasal 12 ayat 1 disebutkan bahwa untuk memperkaya koleksi perpustakaan satuan pendidikan dapat menggunakan bantuan pendidikan dari pemerintah, pemerintah daerah, dan masyarakat dalam bentuk hibah maupun barang. Selain itu sumber dana perpustakaan sekolah juga bisa didapatkan dari dana Bantuan Operasional Sekolah (BOS), di mana berdasarkan Permendiknas Nomor 76 Tahun 2012 tentang Petunjuk Teknis Penggunaan dan Pertanggungjawaban Keuangan Dana BOS, dana BOS yang dapat digunakan untuk pengembangan perpustakaan sekolah minimal $5 \%$ dari dana BOS yang diterima oleh sekolah. Dengan demikian keberadaaan perpustakaan sekolah di lihat dari sisi regulasi sudah sangat memungkinkan untuk berkembang dengan baik karena payung hukumnya sudah mengatur sedemikian rupa tinggal bagaimana aplikasinya di sekolah-sekolah, apakah sudah sesuai dengan aturan atau belum.

Menurut Suhendra (2014: 5-6) secara terperinci, tujuan penyelengggaraan perpustakaan sekolah dasar sebagai beikut: (1) menunjang penyelenggaraan pembelajaran di sekolah dasar, (2) meningkatkan kualitas penyelenggaran pembelajaran di sekolah dasar, (3) menyediakan sarana untuk belajar membaca, menulis, dan menghitung para siswa, (4) membantu para siswa mendapatkan bahan pustaka yang dibutuhkannya baik untuk menunjang kegiatan pembelajaran maupun untuk bahan bacaan, (5) meningkatkan pengetahuan dan keterampilan para siswa, (6) membantu para guru mendapatkan bahan-bahan penunjang pengajaran, (7) mempercepat proses penguasaan teknik membaca, (8) menumbuhkan kebiasaan membaca pada para siswa, (9) 
memperkaya pengalaman belajar para siswa, dan (10) menanamkan kebiasaaan belajar mandiri para siswa.

Kemampuan literasi informasi dan penguasaan teknologi informasi dan komunikasi sangat penting di lingkungan perpustakaan. Kemampuan literasi informasi dalam layanan perpustakaan tidak hanya dibutuhkan untuk mengoptimalkan penggunaan sumber daya perpustaka dalam pengajaran, pembelajaran dan penelitian, tapi juga untuk melatih pengguna untuk mengenal sumber-sumber informasi dan menemukan informasi yang sebenarnya dari berbagai sumber elektronik yang ada (Mishra, 2010).

Di sini perpustakaan memiliki peran penting melalui pengajaran information skills yang

dapatdiimplementasikan dalam program literasi informasi. Kemampuan menggabungkan dan membangun informasi yang ada untuk dapat menciptakan pengetahuan yangbaru. Perkembangan teknologi informasi telah membawa perubahan drastis dalam pengadaan, organisasi, manajemen dan penyebarluasan informasi (Mishra, 2010).

\section{METODE}

Metode yang ditawarkan untuk memecahkan masalah adalah dengan melaksanakan pelatihan secara menyeluruh (teori dan praktik) sehingga kemampuan petugas atau guru yang ditempatkan diperpustakaan dapat ditingkatkan dalam pengelolaan perpustakaan sekolah berbasis teknologi informasi. Agar tujuan dapat dicapai secara maksimal, maka metode pendekatan dilakukan berupa proses tahap demi tahap.Pertama, Penulisan Modul Pengelolaan Perpustakaan Sekolah Berbasis Teknologi Informasi yang terdiri dari pengertian dan pentingnya perpustakaan sekolah, hakikat, fungsi dan tujuan perpustakaan sekolah, dasar-dasar teknologi informasi perpustakaan, penerapan teknologi informasi di perpustakaan, kebutuhan perangkat dan software perpustakaan sekolah SLiMS. Kedua, penyajian materi sesuai dengan isi buku pedoman pengelolaan perpustakaan sekolah berbasis teknologi informasi. Penyajian dilakukan dengan metode ceramah dibantu dengan media power point dan diskusi kelompok.

Ketiga, pelatihan dengan bimbingan individu. Pelatihan difokuskan kepada membuat pengenalan SLiMS, instalasi SLiMS source code, instalasi psenayan, instalasi SliMS di OS lain, pengenalan dan praktik modul system, pengenalan dan praktik bibliography dan master file, pengenalan dan praktik modul pelaporan, pengenalan pembuatan barcode dan kartu anggota menggunakan SliMS, pengenalan dan praktik jaringan komputer sederhana optimalisasi SliMS. Keempat, sosialisasi literasi informasi. Kegiatan sosialisasi ini dikuti semua waraga sekolah yang terdiri dari kepala sekolah, wakil kepala sekolah, guru, pengelola perpustakaan sekolah dan siswa. Sosialisasi literasi informasi kegiatan ini difokuskan pada gerakan literasi informasi dan Implementasi Literasi Informasi di Era Informasi disekolah .

\section{HASIL DAN PEMBAHASAN}

Pelaksanaan Ipteks bagi Masyarakat (IbM) diawali dengan persiapan pelaksanaan yaitu pemantapan jadwal yaitu penentuan jadwal konkrit bersama mitra setelah usulan kegiatan disetujui untuk dilaksanakan. Dalam menentukan jadwal dikoordinasi dengan pihak terkait, terutama LP2M UNP beserta mitra melakukan pengurusan izin pelaksanaan kegiatan. Kedua, rekrutmen peserta: peserta sebanyak 9 orang yang terdiri dari pengelola perpustakaan SMA Negeri 2 dan SMA Negeri 3 Padang. Rekrutmen peserta dilakukan atas kerjasam Tim Pelaksana dengan kepala sekolah.

Ketiga, persiapan materi pelatihan berupa penulisan modul pelatihan untuk memudahkan peserta pelatihan memahami dan mengaplikasikan SliMS. Modul ini berisi pengenalan terhadap aplikasi SliMS mulai dari fitur dan sejarahnya dilanjutkan dengan instalasi SliMS. Di dalam modul juga di jelaskan pra instalasi berkaitan dengan mendefinisikan kebijakan perpustakaan dan persiapan perangkat keras dan lunak. Di dalam modul lebih banyak menjelaskan penggunaan aplikasi yang terdiri dari modifikasi dasar template, modul system, master file, modul bibliografi, modul member, modul sirkulasi dan modul report. Keempat, pelaksanaan kegiatandiawali dengan 
pembukaan kegiatan yang dihadiri oleh tim dari LP2M, kepala sekolah, peserta pelatihan dan tim pengabdian masyarakat.

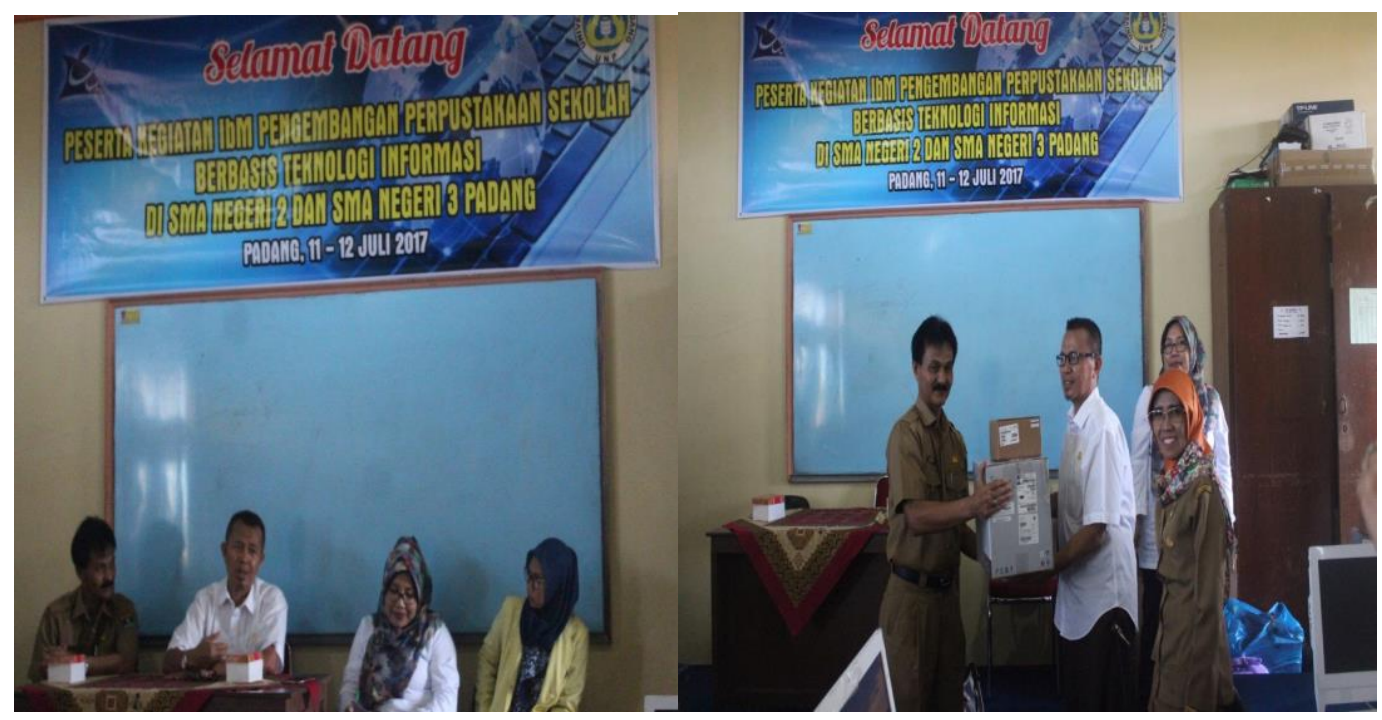

Gambar 1. Pembukaan Kegiatan IbM

Kelima, penyajian materi sesuai dengan isi modul dan penyajian dilakukan dengan metode ceramah dibantu dengan media power point dan diskusi kelompok kecil.

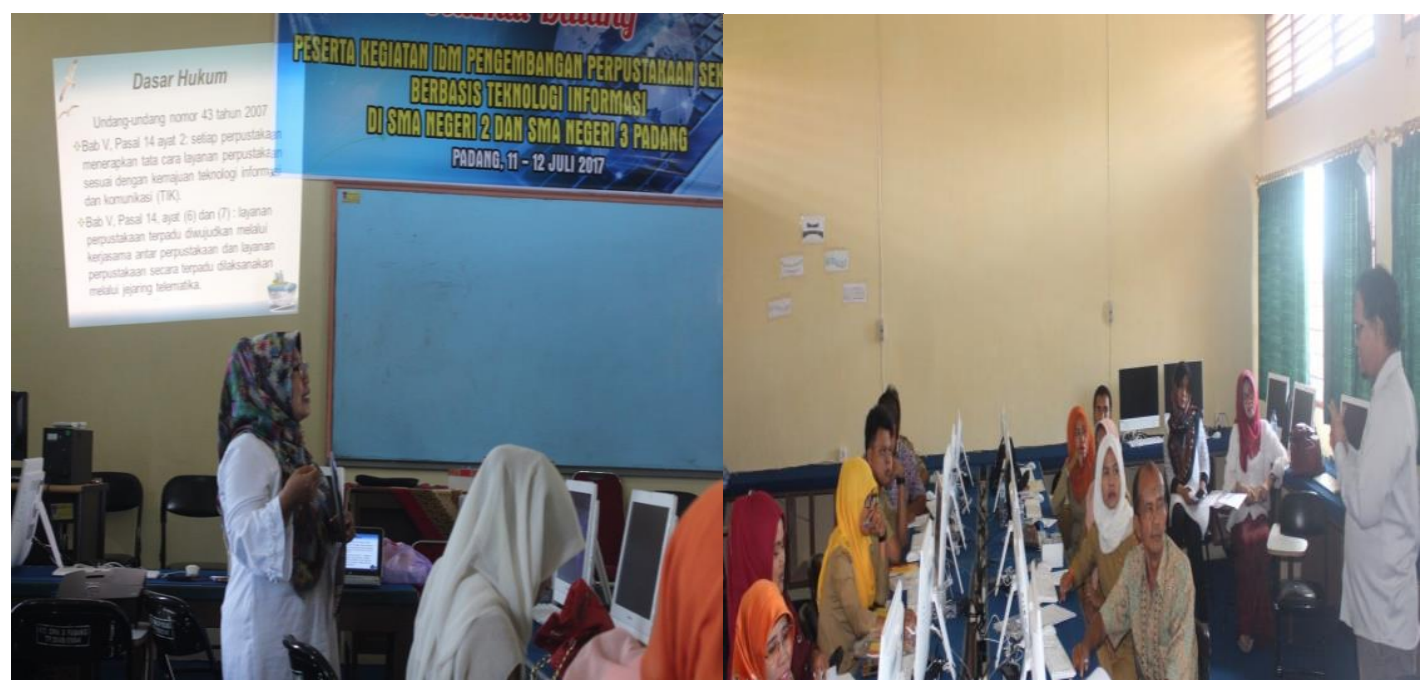

Gambar 2 Penyajian Materi Tim Pengabdian kepada Masyarkat

Keenam, Pelatihan dengan bimbingan individu berupa praktik pengimputan data. Praktik pengimputan data di dampingi oleh tim pelaksana dan peserta pelatihan dibantu mahasiswa melakukan pengimputan data. Peserta mengiput data berdasarkan kelompok koleksi yang dimiliki perpustakaan sekolah. Mengolah koleksi adalah kegiatan rutin yang dilakukan oleh pengelola perpustakaan. Kegiatan ini dinamakan katalogisasi dan klasifikasi. Kegiatan katalogisasi adalah proses pembuatan sarana penelusuran informasi pada koleksi yang dimiliki perpustakaan. Kegiatan katalogisasi pada SliMS adalah kegiatan entri data koleksi berdasarkan standar Anglo American Cataloguing Rules (AACR) dimana koleksi dideskripsikan berdasarkan judul, pengarang, edisi, penerbit, tahun terbit dan sebagainya. 


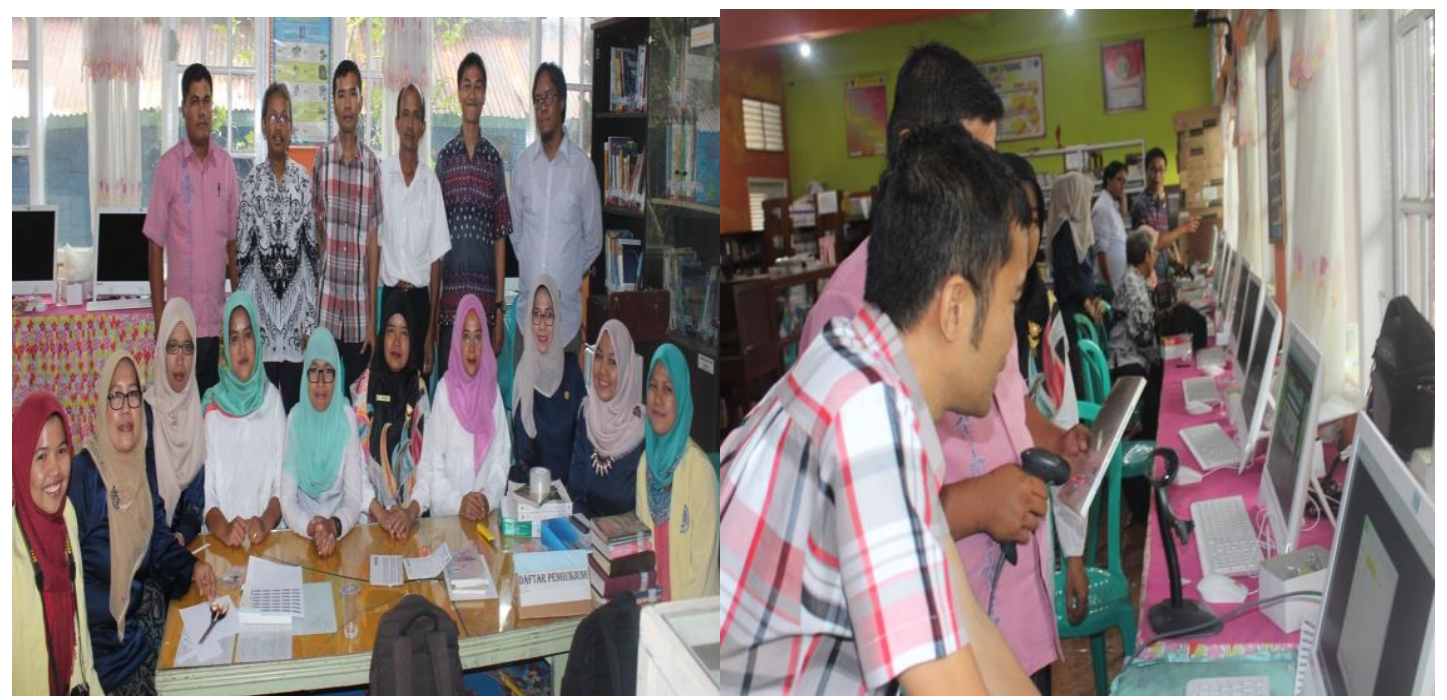

Gambar 3 Praktik Penggunaan Aplikasi SLim

Melaksanakan pelatihan dengan bimbingan individu berupa praktik pembuatan barcode dan kartu anggota. Peserta mempraktikkan cara mencatat jumlah eksemplar setiap koleksi untuk membuat label untuk ditempel pada punggung koleksi serta membuat barcode agar dapat digunakan untuk kegiatan transaksi peminjaman dan pengembalian koleksi. Nomor barcode adalah identitas koleksi yang akan digunakan untuk melakukan transaksi. Untuk itu barcode perlu dicetak agar dapat membedkan antara satu item/eksemplar dengan eksemplar lain. Setelah itu dilanjutkan dengan mengolah data anggota berdasarkan data dan formulir yang telah diisikan anggota. Setelah selesai mengisi data anggota dapat mencetak kartu anggota perpustakaan.

Melakukan pelatihan dengan bimbingan individu berupa praktik penyiapan fisik bahan pustaka. Setelah barcode dicetak dan label punggung di cetak selanjutnya peserta memasang sesuai dengan ketentuan yang berlaku dilanjutkan dengan menyampul buku.

Ketujuh, melakukan simulasi peminjaman dan pengembalian bahan pustaka.Kesembilan melakukan evaluasi baik langsung maupun tidak langsung terhadap peningkatan pengetahuan dan keterampilan peserta dalam mengelola perpustakaan sekolah berbasis aplikasi SLiMS. Proses ini digunakan untuk mengukur kemampuan peserta pada setiap tahap kegiatan. Sehingga tahap kegiatan selanjutnya dapat diperbaiki dan disempurnakan. Teknik yang digunakan untuk mengukur proses kegiatan yang dilaksanakan perpustakaan sekolah adalah observasi, dengan alat berupa panduan observasi. Evaluasi akhir dimaksudkan untuk mengukur ketercapaian tujuan program kegiatan. Indikator keberhasilan adalah pencapaian target luaran kegiatan.

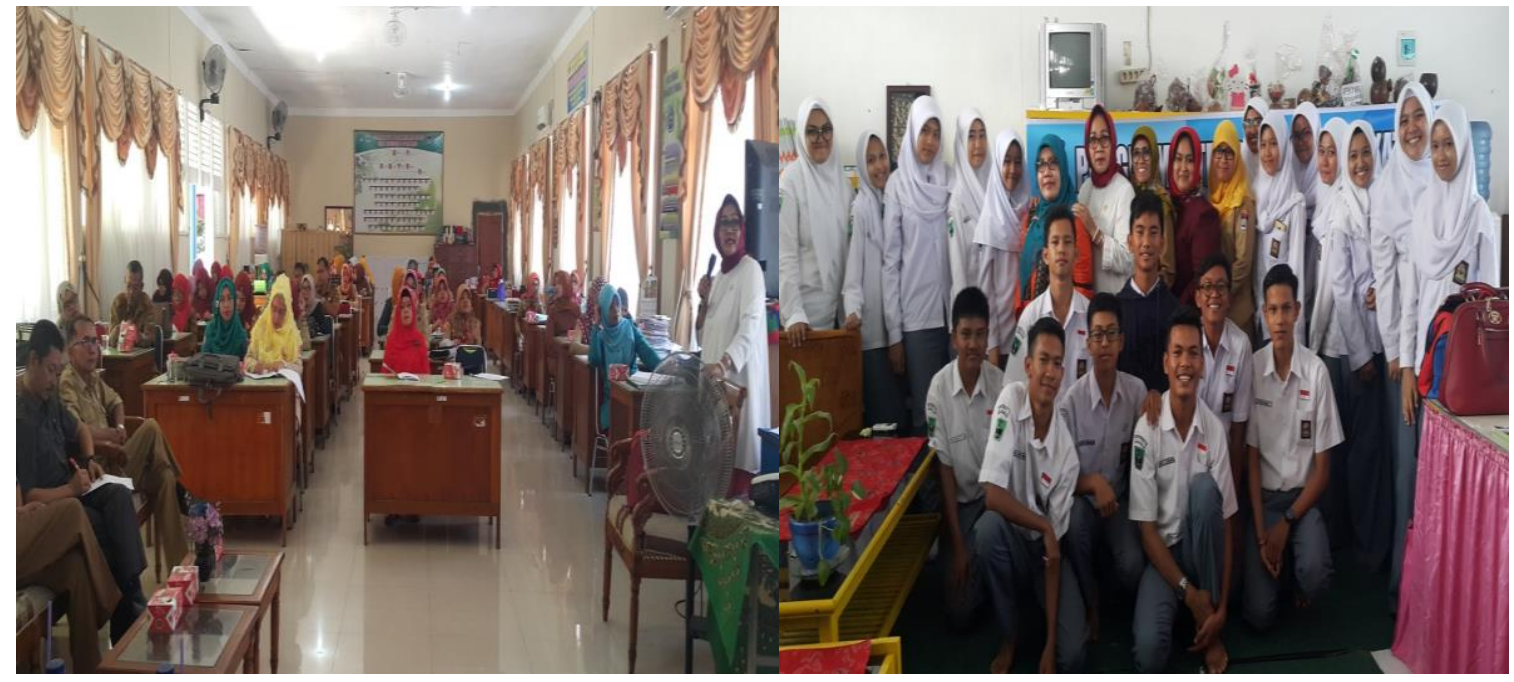

Gambar 4 Kegiatan Sosialisasi Literasi Informasi 
Kedelapan, melakukan kegiatan sosialisasi literasi informasi. Kegiatan sosialisasi literasi informasi yang dilaksanakan dalam kegiatan IbM ini ada tiga kegiatan yaitu sosialisasi literasi dasar, litersi perpustakaan dan literasi teknologi Melalui kegiatan literasi informasi ini harapkan masyarakat sekolah memiliki kemampuan untuk mengidentifikasi, menemukan, mengevaluasi, mengorganisasi dan secara efektif menciptakan, menggunakan, mengkomunikasikan informasi untuk mencari solusi atas masalah yang dihadapi juga merupakan persyaratan untuk berpartisipasi dalam masyarakat informasi dan merupakan hak asasi manusia untuk belajar sepanjang hayat.

\section{KESIMPULAN}

Berdasarkan hasil pelaksanaan pengabdian kepada masyarakat berupa pelatihan pengelolaan perpustakaan sekolah berbasis teknologi informasi dan sosialisasi literasi informasi yang telah dilaksanakan dapat disimpulkan sebagai berikut. Pertama, kegiatan pengabdian kepada masyarakat yang dilaksanakan memberikan manfaat bagi peserta pelatihan terutama dalam meningkatkan pengetahuan dan konsep pengelolaan perpustakaan sekolah berbasis teknologi informasi dengan menggunakan aplikasi Senayan Library Management System (SLiMS). Disamping itu, menanamkan keterampilan pada para peserta pelatihan dalam mengelola dan memanfaatkan perpustakaan sekolah sebagai salah satu sumber belajar di sekolah.

Kedua, kegiatan pelatihandalam hal pengelolaan perpustakaan sekolah berbasis teknologi informasi dapat dijadikan sarana sharing pengetahuan konseptual pengelolaan perpustakaan sekolah berbasis teknologi informasi dengan praktek pelaksanaan pengelolaan perpustakaan sekolah dalam kenyataannya. Ketiga, sosialisasi literasi informasi berbasis teknologi informasi di perpustakaan sekolah dapat dilaksanakan dengan baik. Peserta yang terlibat dalam kegiatan sosialisasi memahami pentingnya peranan perpustakaan untuk memenuhi kebutuhan informasi warga sekolah.

\section{SARAN}

Berdasarkan kesimpulan tersebut, maka saran yang diajukan dari kegiatan pengabdian kepada masyarakat sebagai berikut. (1) bagi pengelola perpustakaan sekolah diharapkan mau menerapkan pengetahuan dan keterampilan yang telah diperolehnya pada saat pelatihan pengelolaan perpustakaan berbasis teknologi informasi, dan (2) kegiatan pelatihan pengelolaan perpustakaan sekolah berbasis teknologi informasi perlu dilaksanakan di masa-masa mendatang sebagai bagian dari Tri Darma Perguruan Tinggi.

\section{UCAPAN TERIMA KASIH}

Penulis mengucapkan terima kasih kepada Kementerian Riset, Teknologi dan PendidikanTinggi, Pimpinan LP2M UNP beserta jajarannya, Pimpinan Fakultas Bahasa dan Seni, dan Mitra dan para peserta kegiatan.

\section{DAFTAR PUSTAKA}

[1] Ishak. 2005. "Pengelolaan Perpustakaan Berbasis Teknologi Informasi".Jurnal Studi Perpustakaan dan Informasi (Pustaha).Vol 4, No 2. Hlm:87-93.

[2] Lasa. 2009. Manajemen perpustakaan sekolah. Yogyakarta: Pinus.

[3] Mishra, R.N dan C. Mishra. 2010. Relevance of information literacy in digital environment. Journal of Emerging Trends in Computing and Information Sciences, 1, 48-54, Diakses dari http://www.cisjournal.org, pada tanggal 15 Oktober 2017.

[4] Yusoff, M, Rahman, S.,A., Mutalib, S., and Mohammed, A. , 2006, Diagnosing Application Development for Skin Disease Using Backpropagation Neural Network Technique, Journal of Information Technology, vol 18, hal 152-159.

[5] Pendit, Putu Laxmana, dkk. 2007. Perpustakaan Digital : Perspektif Perpustakaan Perguruan Tinggi Indonesia. Jakarta: Sagung Seto. 
[6] Pendit, Putu Laxmana. 2008. Perpustakaan Digital dari A sampai Z. Jakarta: Cita Karyakarsa Mandiri.

[7] Rahmah, Elva. "Strategi Perencanaan Perpustakaan Digital dalam Konteks Manajemen".Jurnal Kepustakawanan dan Masyarakat Membaca.Vol. 27, No. 2. Hlm. 1-22.

[8] Sinaga, Dian. 2011. Mengelola Perpustakaan Sekolah. Bandung: Bejana.

[9] Siregar, A. Ridwan. 2004. Perpustakaan: Energi Pembangunan Bangsa. Medan:USU Press.

[10] Suhendar, Yaya. 2014. Panduan Petugas Perpustakaan: Cara Mengelola Perpustakaan Sekolah Dasar. Jakarta: Prenada.

[11] Sulistyo-Basuki. 1993. Pengantar Ilmu Perpustakaan.Jakarta :Gramedia Pustaka Utama.

[12] Sulistyo-Basuki.2003. Perpustakaan Digital Dilihat Dari Titik Pandang Kepustakawanan Indonesia. Jakarta: Media Pustakawan Vol 10 No.1.

[13] Supriyanto, Wahyu dan Ahmad Muhsin. 2008. Teknologi Informasi Perpustakaan:Strategi Perancangan Perpustakaan Digital. Yogyakarta : Kanisius.

[14] Yusuf, Pawit M. 2007. Pedoman Penyelenggaraan Perpustakaan Sekolah. Jakarta: Kentana. 